\title{
Studies on the Properties of Sugarcane Bagasse Fibre for Sustainable Textile Applications
}

\author{
JC Sakthivel $^{1}$, S Brindha ${ }^{1}$, G Gowthamraj ${ }^{1}$ and J Sabna ${ }^{1}$ \\ \{jcs.textile@psgtech.ac.in1\} \\ brindhasrinivasan145@gmail.com,gowthamraj.gu@gmail.com,sabna.1999@gmail.com \\ Department of Textile Technology, PSG College of Technology, \\ Coimbatore - $641004^{1}$
}

\begin{abstract}
Plastic is one of the breakthrough inventions of the mankind. Plastics constitute an important component of the range of materials used in modern society like packaging, construction, transportation, apparels, gardening materials, healthcare, furniture and other applications. Though they have several meritorious properties like chemical inertness, light weight, durability, appreciable strength and flexibility, they are harmful to the environment as they are non-biodegradable in nature. About $40 \%$ of plastics are used in packaging. So, developing reusable and biodegradable materials for packaging and other applications, where plastics are currently used is the need of the hour. New natural textile fibres can be extracted from natural resources and feasibility of using these fibres in suitable applications can be studied. Sugarcane bagasses are excellent sources of fibre which are less utilised now. They can be chemically treated to obtain useful textile fibre with a good amount of yield by proper extraction method. This paper mainly deals with extraction and characterization of fibers produced from bagasse. The extracted fibres have good moisture regain, density and tensile strength. The $100 \%$ bagassefibre needle punched nonwoven was developed successfully and it is suggested to use in the areas like agriculture textiles, geo textiles and suitable technical textiles applications considering sustainability and environment friendliness.
\end{abstract}

Keywords: Biodegradable, Needle punched nonwoven fabric, Packaging wastes, Plastics, Sugarcane bagasse fibres, Sustainability.

\section{Introduction}

Plastics constitute an important component of the range of materials used in modern society. All aspects of our daily life involve plastics or rubber in one form or another in different applications. Though they have several advantages like durability, light weight, flexibility, etc., they are non-biodegradable and are toxic to the environment. Plastics find applications mainly in packaging, construction, transportation, apparels, gardening materials and so on. About $40 \%$ of plastics are used in packaging which includes food packaging, dry packaging, protection, packaging and vending packaging. And most of it is disposable and is used just once and then discarded.

In a recent survey, it has been found that; $25 \%$ of consumers are extremely concerned about plastic packaging, $42 \%$ of consumers think manufacturers should prioritize recyclable packaging and $21 \%$ of consumers think the industry should set up a system for packaging that is completely free of plastic.So developing reusable and biodegradable materials for 
packaging is the need of the hour [3]. Not only for packaging, is replacing plastics in other areas definitely a good way to prevent the environmental damage. There are many alternatives available like bio plastics, materials from the shrimp shells, papers, natural fibres, cornstarch, and synthetic biopolymers. Not all the biodegradable materials can be easily produced in an eco-friendly manner. The material which is abundantly available, easily process able and gives good yield will be a suitable alternative.

Natural fibres which are extracted through chemical process have gained renewed interest over the last decade due to their varied use in textile, composite, handicrafts and packaging[2]. Bagasse fibres are one such example of natural fibre which is available easily[1]. Sugarcane is used to make sugar or juice and the leftover material (bagasse) is used as fuel mostly [6]. The fibre has good properties and will be a potential replacement for plastics in a few areas [4]. On a yearly basis approximately 240 million tonnes of bagasse is produced which can be put to good use. Extraction of sugarcane bagasse fibres can be done by mechanical, chemical or steam explosion method. Fibres extracted in mechanical process are normally small and cannot be used for technical processes. In chemical treatment, the stalks are pre-treated in water and further treated with $\mathrm{NaOH}[5]$.

Though plastics possess several good mechanical and durable properties, they are harmful to the environment as they are also non-biodegradable, which makes them to take centuries to degrade. Micro plastics are present threat that humanity need to face. This also affects the marine food chain. So, developing a biodegradable material which moreover serves as a replacement of plastic is the prime objective of this work. Utilizing sugarcane bagasse as a source material for this work seems to be an efficient and economic path. The objectives of this study are, to extract fibre from sugarcane bagasse by chemical extraction, to characterize the extracted fibres, to develop needle punched non-woven samples and to test the developed samples for suitable textile applications.

\section{Materials And Methods}

\subsection{Fibre extraction}

Sugarcane bagasse fibres are extracted by method of chemical retting using Sodium hydroxide. The sugarcane bagasses were collected from nearby juice shops and the stalks were cut to the length of 3 to 4 inches ensuring the absence of nodes. The inner pith portion which contains soft plant tissues and gummy substances were manually removed and outer rind is used.The cut rind portion of sugarcane bagasse was pre-treated in hot water at $90^{\circ} \mathrm{C}$ with M:L ratio of 1:50 for 60 minutes. The colouring matter in sugarcane stalks and sugar traces get removed in this treatment[8].Then the bagasses were dried at room temperature.The fibre yield by manual method was $0.9 \%$ and $8.69 \%$ when extracted by mechanical method. The pretreated bagasses were treated with $0.1 \mathrm{~N} \mathrm{NaOH}$ at $100^{\circ} \mathrm{C}$ for 4 hours. M:L ratio is 1:100. Continuous stirring was done along the process and then the fibres are dried at room temperature[10].The figure 1 shows the extracted and treated bagasses. 


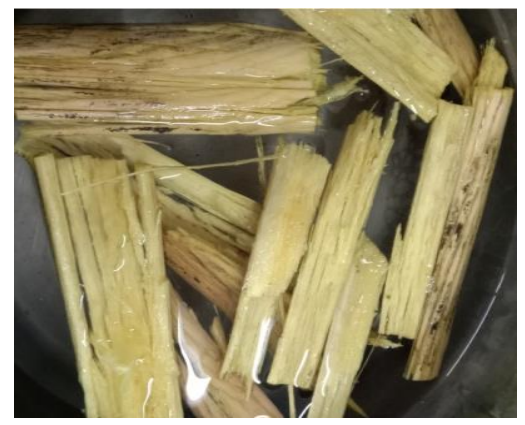

Figure 1 Treated bagasses

\subsection{Production of needle punchednonwoven sample}

The mechanically extracted fibres were well opened and formed as a web in miniature fibre opener cum web former machine which is mostly used for long staple fibres. The machine contains a pinned beater which is suitable for coarse opening of bast fibres. The formed web is pressed 3 times in the delivery roller of this machine. The beater speed was 350 rpm. By this method a thick web of sugarcane bagasse fibres is formed.The formed web is then needle punched to achieve the desired nonwoven fabric in the needle punching machine. The following are the process parameters maintained during the needle punching process: Number of punches per minute is 50 , Feed rate is $20 \mathrm{~mm}$ per stroke, Punch density is 50 needles per square inch and Penetration depth is $10 \mathrm{~mm}$. By this method the $100 \%$ sugarcane bagasse fibres needle punched nonwoven fabric was produced as shown in Figure 2.

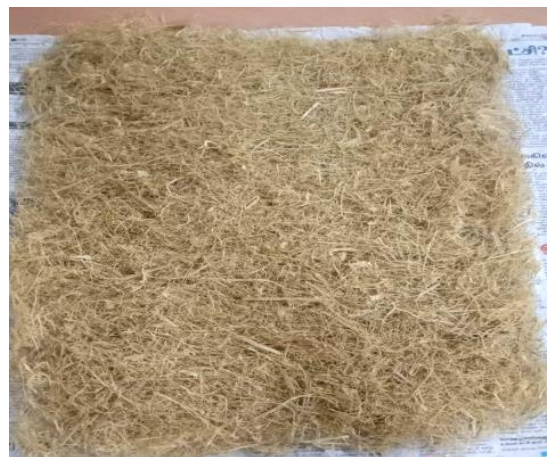

Figure 2. 100\% Sugarcane bagasse fibres needle punched nonwoven fabric

\subsection{Testing methods}

The extracted sugarcane bagasse fibres are tested for various physical and mechanical properties and the results are obtained.The fibre diameter can be tested by using Air wedge method. The tensile strength and elongation testing was carried out using Zwick Roell tester under the principle of Constant rate of elongation. The standard used in this testing was ASTM 4035 (specimen length $50 \mathrm{~mm}$ and test speed $30 \mathrm{~mm} / \mathrm{min}$ ). The fineness of extracted sugarcane fibre is tested by gravimetric method. The test was carried out according to ASTM D 1577-07 standards. By this method the fineness of the fibre can be calculated in terms of Tex. The moisture regain value of extracted bagasse fibres are tested by a hot air oven method. This is the basic method of measuring moisture regain. The sample is first weighed and taken 
as $\mathrm{m} 1$, then dried in a hot air oven at $100^{\circ} \mathrm{C}$ for 1 hour and then weighed again and taken as $\mathrm{m} 2$. The standard used was ASTM D 2495 [11].The density of the extracted bagasse fibres is interpreted using density gradient column method. When fibres are dropped in, they sink to the point at which the fibre density equals the liquid density and remain suspended there. Calibration of the tube is done by sinking fibres of known densities (cotton and polyester) floating at their appropriate levels. Both graphical method and interpolation method can be used for determining the density of fibre. The Standards used was ASTM D8171-18.

The areal density of the produced non-woven fabric was tested by cutting a square of dimension $10 \mathrm{~cm} \times 10 \mathrm{~cm}$, weighing it and multiplying the obtained weight by 100 .Thickness of the non-woven fabric was tested by using thickness gauge. The Matt is placed in the thickness gauge and thickness is noted as average for the non-woven fabric. The Standards used was ASTM D1777-96. The tensile strength and elongation of needle punched nonwoven was tested under the principle of Constant rate of elongation with ASTM 5035 standards. The sample size is $75 \mathrm{~mm}$ lengthwise and $50 \mathrm{~mm}$ widthwise. The gauge length is $75 \mathrm{~mm}$. The abrasion resistance of the needle punched nonwoven fabric was tested in abrasion tester [9]. The testing speed was 90 cycles per minute and the sample was tested for 750 cycles. The abrasion resistance of the sample was tested by means of weight loss percentage. The weight of the samples before and after the test was noted and abrasion resistance was calculated.The thermal conductivity of the needle punched nonwoven was calculated using Lee's disc experiment.

\section{Results And Discussion}

\subsection{Properties of sugarcane bagasse fibres}

The microscopic structure of the bagasse fibres were studied using scanning electron microscopy. Figure 3 shows the Longitudinal view of theSugarcane bagasse fibres and Figure 4 shows the cross sectional viewof theSugarcane bagasse fibres. The scanning electron microscopy photographs of sugarcane bagasse fibres show that the fibre is multicellular and the cross section is irregular with no standard shape. Surface seems to be flagellated. The longitudinal surface are with striations and not completely smooth. The effect of alkali treatment was clearly visible in the longitudinal view as the fibres are well separated from the fibrous bundles and the lignin and other binding gummy substances were well removed. The fibre is solid with irregular cross sectional shape. It is also noted that the pores or hollow void spaces are not present in the cross section of the fibre.

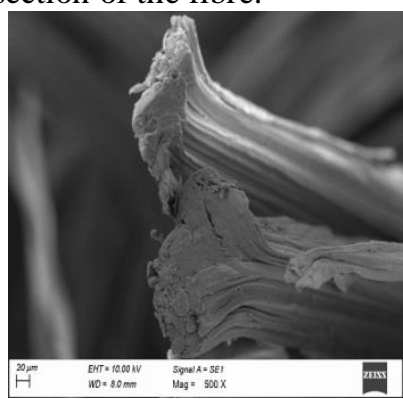

Figure 3 Longitudinal view of Sugarcane bagasse fibre 


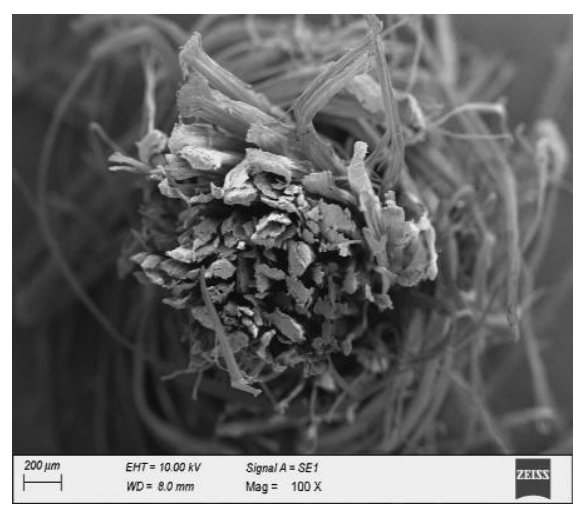

Figure 4 Cross-sectional view of Sugarcane bagasse fibre

The extracted sugarcane bagasse fibres are tested for length and the mean length of fibres were found to be 3 to 4 inches. The mean diameter of manually extracted fibres is 84.44 microns. The mean diameter of mechanically extracted fibres is 122.03 microns. Mean tenacity of fibre is found to be 26.8 grams/denier and elongation $\%$ is 2.7 . The mean linear density of bagasse fibre is $50 \mathrm{Tex}$. The moisture regain of the fibre is $6.07 \%$. The density of fibre was found to be $1.42 \mathrm{~g} / \mathrm{cc}$. When the fibres are ignited they burned with an orange flame and the flame propagated quickly throughout the sample. After burning the fibres showed afterglow effect for a few seconds. The ash was greyish black and the smell was like burnt paper. This preliminary test shows that the fibre is made up of cellulose. In the solubility test, the fibres dissolved in $80 \%$ Sulphuric acid at room temperature. This confirmatory test showed that the fibre is cellulosic in nature. The figure 5 shows the burning behaviour of fibre and figure 6 shows the solubility behaviour of sugarcane bagasse fibre.

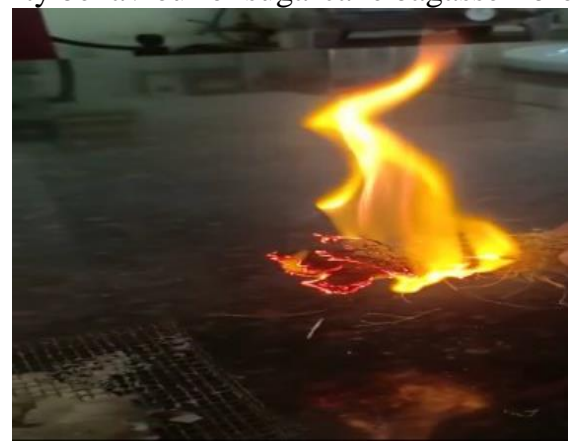

Figure 5 Burning behaviour of sugarcane bagasse fibre

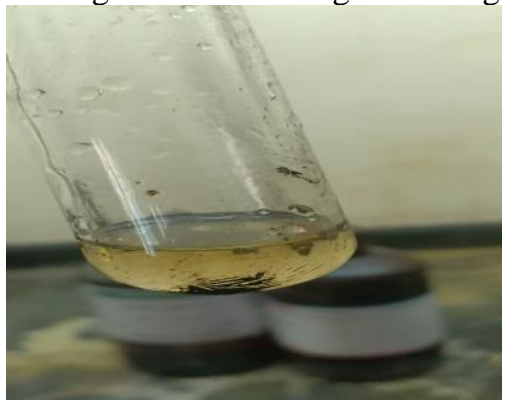

Figure 6 Solubility behaviour of sugarcane bagasse fibre 


\subsection{Properties of sugarcane bagasse fibre nonwoven fabrics}

The areal density of the produced sugarcane bagasse fibreneedle punched non-woven was found to be $472 \mathrm{~g} / \mathrm{sq} . \mathrm{m}$. Mean thickness of the needle punched nonwoven is $5.69 \mathrm{~mm}$. The tensile strength of the nonwoven is 92.1 grams and elongation is $43.61 \%$ [7]. The abrasion resistance of the sample shows weight loss of $26.97 \%$. The mean thermal conductivity was found to be $0.050496 \mathrm{~W} / \mathrm{mK}$. This value of thermal conductivity corresponds to a thermal insulation of 0.726 clo. By using the above experimental results several other properties are calculated for nonwoven fabric. They are like Porosity is 94.15 percent, Fibre volume fraction is 5.85 percent and Fabric density is $83.025 \mathrm{Kg} / \mathrm{m}^{3}$. The above results shows that the sugarcane bagasse fibreneedle punched non-woven can be used in packaging, agro textiles and geo textiles application.

\section{Conclusion}

Sugarcane bagasse fibreneedle punched non-wovenmade up of the extracted fibres was produced in aim of reducing the usage of non-biodegradable materials. The raw material required for this is, easy to obtain and the fibres also have good properties. Also the fabrics are found to be suitable for different technical textile applications likepackaging, agro textiles and geo textiles. The fibre yield by manual method was $0.9 \%$ and $8.69 \%$ when extracted by mechanical method. There were difficulties in manual extraction whereas it was easier through mechanical method and the yield also was higher. The needle punched non-woven produced also has favourable properties. As the abrasion resistance and thermal behaviour of the Sugarcane bagasse fibreneedle punched non-woven is also good it can be used as insoles as thermal protective layers. Water retention properties are good and so it is suitable for agro textile uses. The cost effective and environmental friendlysugarcane bagasse fibreneedle punched non-woven can finds suitable applications, where water retention and minimum strength is required.

\section{References}

[1] Ovidiu Julius Chiparus. Bagasse Fiber for Production of Nonwovens Materials.Lsu(Doctoral Disserations.[2004]).

[2] DavinaMichel,BrunoBachlier,Jean Yves Drean. Preparation of Cellulosic Fibres from Sugarcane for Textile Use.Hindawi Conference Papers -Material Scienc. 2013.

[3] Amir Hooman, Hemmasi, Ahmad Samariha, AsgharTabei, Mohammad Nemati\&AlirezaKhakifirooz (2011):Study of morphological and chemical composition of fibres from Iranian sugarcane bagasse. American Eurasian journal of agriculture and environmental science.

[4] S D Asagekar,V K Joshi (2014) .Characteristics of Sugarcane Fibres. Indian Journal of Fibres and Textile Research(Vol-39, pp.180-184).

[5] K Gokul, T Ram Prabhu, T Rajasekaran (2017). Processing and Evaluation of Mechanical Propertiesof Sugarcane Fiber Composites. Trans Indian Inst Met.( vol-70, pp.2537- 2546)

[6] TshwafoE Motaung, MokgaotsaJ Mochane (2017). Systematic review on recent studies on bagasse and cellulose polymer composites.Journal of thermoplastic composites.

[7] Chung-Feng Jeffrey Kuo, Te-Li Su, And Cheng-Ping Tsai (2007) .Optimization of the Needle Punching Process for the Nonwoven Fabrics with multiple Quality Characteristics By Grey-Based taguchi Method. (Vol-8, pp.654-664) 
[8] KullasatriSaelee, NaiyasitYingkamhaeng, PrakitSukyai. Extraction and Characterisation of Cellulose From Sugarcane Bagasse by using Environmental Friendly Method. Thai Society for biotechnology and International Conferencein 2014.

[9] VinayKumar Midha (2011). Study of Stiffness and Abrasion Resistance of Needle-Punched Nonwoven Blankets. The Journal Of The Textile Institute.(102, pp. 126-130)

[10] GlauberCruz, Patricia A, Santiago, Carlos E (2018).Investigation into the Physical-Chemical Propertieso Chemically Pretreated Sugarcane Bagasse. Journal of Thermal Analysisand Calorimeter .

[11] J.L Guimareasa, E. Frollini B, C.G. Da Sliva B (2009). Characterization of Banana, Sugarcane Bagasseand Sponge Gourd Fibres of Brazil. Elsvier, Industrial Crops and Products.(Vol30, pp.407-415).

[12] R. Abirami, D.S. Vijayan, Sijo Joseph John, Aldrin Albert, and Alfred Koshy Alex, Experimental Study on Concrete Properties Using Pineapple Leaf Fiber, International Journal of Advanced Research in Engineering and Technology, 11(6), 2020, pp. 913-920, DOI: 10.34218/IJARET.11.6.2020.082 